\title{
Upper airway inflammation and respiratory symptoms in domestic waste collectors
}

\author{
I M Wouters, S K M Hilhorst, P Kleppe, G Doekes, J Douwes, C Peretz, D Heederik
}

See end of article for authors' affiliations

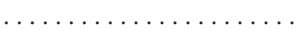

Correspondence to: Dr D Heederik, Institute for Risk Assessment Sciences (IRAS), Division of Environmental and Occupational Health, Utrecht University, Yalelaan 2. PO Box 80176,3508

TD Utrecht, The

Netherlands:

d.heederik@|ras.uu.nl

Accepted 27 July 2001

\begin{abstract}
Objectives: To compare respiratory symptoms and upper airway inflammation in domestic waste collectors and controls, and to find the association between measures of upper airway inflammation on the one hand and exposure concentrations of organic dust or respiratory symptoms on the other hand. Methods: In a cross sectional study among 47 waste collectors and 15 controls, questionnaire data on respiratory symptoms were collected. Nasal lavage (NAL), to assess upper airway inflammation, was performed before and after a work shift at the beginning and at the end of the working week. In NAL fluid, cells were counted and differentiated and concentrations of interleukin 6 (IL6), IL8, tumour necrosis factor- $\alpha(T N F \alpha)$, and IL $1 \beta$ were measured. In collectors, inhalable dust samples were collected in which bacterial endotoxin and mould $\beta(1 \rightarrow 3)$-glucan were assessed.

Results: Prevalence of respiratory symptoms was higher in waste collectors than in controls. Geometric mean exposure concentrations were $0.58 \mathrm{mg} / \mathrm{m}^{3}$ for dust, $39 \mathrm{EU} / \mathrm{m}^{3}$ for endotoxin, and $1.3 \mu \mathrm{g} / \mathrm{m}^{3}$ for $\beta(1 \rightarrow 3)$-glucan. At the end of the week collectors had higher concentrations of total cells and IL 8 in NAL before and after a shift than controls (cells, before 1.9-fold $p<0.10$, after 3.3-fold $p<0.01$; IL8, before and after 1.8-fold $p<0.05$ ), and after/before work shift ratios of total cells were also higher (2.3-fold $p=0.06$ ) in collectors than in controls. Cells in NAL fluid consisted predominantly of neutrophils and epithelial cells, whereas eosinophils and mononuclear cells were rarely found. Exposure to dust and endotoxin was associated with concentrations of IL8 after the shift ( $<<0.05)$. Increased concentrations of IL8 $(p<0.05)$ and total cells $(p<0.10)$ after the shift were associated with respiratory symptoms. Concentrations of IL6, TNF $\alpha$, and IL $1 \beta$ were not associated with waste collecting, symptoms, or exposure.

Conclusions: Waste collectors show signs of increased upper airway inflammation and respiratory symptoms compared with controls. Exposure to organic dust probably underlies the inflammation mediated by neutrophils that result in respiratory symptoms.
\end{abstract}

s ncreased numbers of workers are involved in the household waste recycling industry, due to the recently introduced separate collection of organic and non-organic household waste in several European countries, as part of national or local environmental management policies. The health risks associated with this type of industry are, however, not yet clear. The few studies that assessed health risks ${ }^{1-6}$ showed that workers in waste handling, particularly workers collecting and processing domestic organic waste for composting, are at risk of developing various health effects-such as respiratory symptoms, systemic influenza-like symptoms, and gastrointestinal problems.

It is not clear which specific exposures and underlying mechanisms may induce these health effects. Waste workers are exposed to a heterogeneous mixture of bioaerosols, gases, and vapours-such as microbial and non-microbial volatile organic compounds. ${ }^{7-9}$ Moulds may induce allergic reactions, and case reports of hypersensitivity pneumonitis and allergic bronchopulmonary aspergillosis have been published. ${ }^{2} 10$ However, allergic diseases are rarely reported in surveys and are unlikely to explain the occurrence of most respiratory symptoms. Alternatively, non-allergic inflammatory reactions may be important, especially due to dust containing endotoxins and $\beta(1 \rightarrow 3)$-glucans, two known proinflammatory cell wall components of gram negative bacteria and most fungi, respectively. ${ }^{5-7}$ 12-15 $^{15}$ The production of proinflammatory cytokines-such as interleukin-1 $\beta$ (IL1 $\beta$ ), interleukin-6 (IL6), interleukin-8 (IL8), and tumour necrosis factor- $\alpha$ (TNF $\alpha)-$ plays a major role in these inflammatory processes. ${ }^{16}{ }^{17}$

Recently, two studies have specifically related exposure to bioaerosol to the presence of airway inflammation and subse- quent symptoms in workers in the household waste collecting ${ }^{5}$ and organic waste composting industry. ${ }^{6}$ In these studies, airway inflammation seemed to be mainly mediated by neutrophils and was independent of specific antibodies, probably caused by direct interaction of inflammatory biological agents such as endotoxins or glucans with epithelial tissues and infiltrating white blood cells. As these studies were small and associations were weak, no firm conclusions could be drawn as to which agents and underlying mechanisms may be responsible for the symptoms. Furthermore, due to the small study populations, confounding variables-such as smoking, age, and atopy-could not be dealt with appropriately in these studies.

In the present study we therefore investigated prevalence of respiratory symptoms and upper airway inflammation in a larger population of domestic waste collectors and controls. In all subjects nasal lavage (NAL) was performed before and after the work shift, to assess acute across shift effects, and at the beginning and at the end of the week, to assess across week effects. We assessed differences between waste collectors and controls by comparing concentrations before and after the shift of NAL variables and after/before shift ratios of NAL variables. Associations between markers of upper airway inflammation and exposure concentrations of dust, endotoxin, and glucan, and prevalence of respiratory symptoms were also assessed.

Abbreviations: NAL, Nasal lavage; IL1 $\beta$, interleukin-1 $\beta$; IL6, interleukin-6; IL8, interleukin-8; TNF $\alpha$, tumour necrosis factor- $\alpha$; PR, prevalence ratio 


\section{Main messages}

- Household waste collectors are exposed to microbia agents - such as bacterial endotoxins and $\beta(1-3)$-glucans irrespective of the type of rubbish they handle.

- Domestic waste collectors showed signs of increased prevalence of respiratory symptoms and showed increased concentrations of variables indicative of upper respiratory inflammation in nasal lavage compared with controls.

- The exposure to microbial agents is probably associated with the increased prevalence of respiratory symptoms and variables indicative of upper respiratory inflammation in nasal lavage fluid.

- Within the group of waste collectors a dose-response relation between exposure and increased concentrations of inflammatory variables in nasal lavage fluid was found.

- People with respiratory symptoms more often had increased concentrations of inflammatory mediators, especially IL8 and increased numbers of cells in nasal lavage fluid.

\section{Implications}

- Exposure of waste collectors to microbial agents is relatively low. Despite the low levels, a respiratory inflammatory response is measurable. The importance of this response for long term effects is not known but needs to be established.

\section{METHODS}

\section{Subjects and process description}

All domestic waste collectors of the municipal waste collecting facilities of four large Dutch cities (over 100000 inhabitants) were approached to participate in the current study. Participants were approached by the facilities due to privacy regulations. As a result no information could be obtained on response rate, as the total number of people approached by the facility was not available to us, and consequently no information on characteristics of non-responders could be obtained.

Three major job tasks were distinguished: driving, loading, and driving/loading (driving and loading were carried out alternately on the same day). During the week, job task rotation occurred. Collected waste was either non-separated mixed waste or separated organic and non-organic/residual waste fractions. As well as the waste collectors, office workers of the same four facilities were included as unexposed controls. The offices of the office workers were about 100-600 $\mathrm{m}$ from the garage where the waste collecting trucks were parked, and thus were not likely to be as highly exposed to organic dust as waste collectors.

\section{Study design}

Fieldwork was performed from June to September 1997. All subjects filled out a health questionnaire and underwent nasal lavage (NAL) before and after the work shift at the beginning and at the end of the week, for a period of $1-2$ weeks. The NAL was conducted on Monday or Tuesday (beginning of the working week) and on Wednesday, Thursday, or Friday (end of the working week), always allowing 2-3 days between NALs at the beginning and end of the working week. Each person had between two and eight NALs. In waste collectors only, personal exposure measurements were performed at the same days as the NALs resulting in 1-4 exposure measurements per collector. In total 47 waste collectors and 15 controls participated in the NAL, questionnaire, and exposure measurement (for collectors only) as part of the research protocol. Thirty six waste collectors and 11 controls also provided a blood sample for serology measurements. The medical ethics committee of Wageningen University approved the study and participants gave informed written consent.

\section{Questionnaire}

A self administered questionnaire was developed specifically for the waste recycling and composting industry ${ }^{18}$ and comprised questions from the British Medical Research Council respiratory symptoms questionnaire, ${ }^{19}$ questions about symptoms suggestive of respiratory allergies and hyperresponsiveness, ${ }^{20}$ and questions about upper and lower respiratory symptoms during the past year. ${ }^{2421}$ Also, questions on job history and smoking habits were asked.

\section{Serology}

Serum samples were collected by venipuncture. In the serum total IgE and specific IgE against common allergens (grass pollen mix, birch pollen, house dust mite, and cat dander) and specific IgE against mould allergens (Cladosporium species (mixed Cladosporium cladosporiodes, Cladosporium elatum, Cladosporium herbarum), Aspergillus species (mixed Aspergillus versicolor, Aspergillus fumigatus, Aspergillus amstelodami, Aspergillus nidulans), Penicillium species (mixed Penicillium brevicompactum, Penicillium expansum, Penicillium notatum, Penicillium commune), and Aspergillus fumigatus) were measured by an enzyme immunoassay as described previously by Doekes et al. ${ }^{22}$ All allergens were obtained as lyophilised extracts from ALK (Nieuwegein, The Netherlands).

\section{Nasal lavage}

Nasal lavage (NAL) was performed as described previously. ${ }^{6}$ Cells in the NAL fluid were counted and a cytospin was made for cell differentials. Interleukin-6, IL8, ILI $\beta$, and TNF $\alpha$ were measured in the fluid by enzyme immunoassays (Biosource, Biosource Europe SA, Fleurus, Belgium). The limits of detection were $45 \mathrm{pg} / \mathrm{ml}$ for TNF $\alpha, 6.2 \mathrm{pg} / \mathrm{ml}$ for ILI $\beta, 0.5$ $\mathrm{pg} / \mathrm{ml}$ for IL6, and $2.5 \mathrm{pg} / \mathrm{ml}$ for IL8.

\section{Exposure measurements}

Full shift personal inhalable dust samples were collected with Gillian P5 portable constant flow pumps at a flow rate of 3.5 $1 /$ min in combination with GSP-samplers ${ }^{23}$ equipped with Whatman GF/A glass fibre filters ( $37 \mathrm{~mm}$ diameter). Dust, endotoxin, ${ }^{24}$ and $\beta(1 \rightarrow 3)$-glucan ${ }^{25}$ measurements were performed as described previously. Limits of detection were 0.2 $\mathrm{mg} / \mathrm{m}^{3}$ for dust, $4 \mathrm{EU} / \mathrm{m}^{3}$ (endotoxin units) for endotoxin, and $0.26 \mu \mathrm{g} / \mathrm{m}^{3}$ for glucan.

\section{Statistical analysis}

Data were analysed with SAS statistical software (version 6.12; SAS institute, Cary, NC, USA). Concentrations that were below the limits of detection were assigned a value of two thirds of the detection limit. ${ }^{26}$ To assess acute (across shift) effects, after/before shift ratios of total cell, IL8, and IL6 concentrations were calculated. Levels of exposure, NAL variables, and NAL after/before shift ratios were natural log transformed before statistical analysis to ensure normality of the data. Because of high numbers of non-detectable concentrations of TNF $\alpha$ and ILI $\beta$ in NAL measurements (both 74\%), TNF $\alpha$ and IL1 $\beta$ data were dichotomised based on the limit of detection (detectable versus non-detectable), and acute effects were not studied.

A mixed effects models (an extension of multiple regression analysis for correlated observations) were used to analyse relations between NAL and being a collector or control, between NAL and exposure, and between exposure and exposure determinants correcting for first order autocorrelation between repeated measurements and with and without adjustment for potential confounding variables. By including an interaction term for exposure (collector $v$ control) and day of the week (beginning $v$ end of the week NAL) differences in across week changes were tested for. Also, we applied mixed models to obtain estimates of variance of the dependent variable within and between subjects. Mixed model linear 
Table 1 Population characteristics and symptom prevalence in waste collectors and controls of four Dutch municipal waste facilities

\begin{tabular}{lll}
\hline Characteristics & Controls & Waste collectors \\
\hline$n$ & 15 & 47 \\
Age (y, mean(SD)) & $36.4(6.4)$ & $34.0(10.2)$ \\
Duration of employment & $78(49-128)$ & $63(6-155)$ \\
(months, median (25\%-75\%)) & & \\
Employed<6 months (\%) & 0.0 & $21.7^{*}$ \\
Male (\%) & 86.7 & $100.0^{*}$ \\
Current smoker (\%) & 40.0 & 65.2 \\
\hline
\end{tabular}

${ }^{*} \mathrm{p}<0.05 \chi^{2}$ test waste collectors $v$ controls.

regression analyses were used for continuous variables and mixed model multiple logistic regression analyses for dichotomised variables. ${ }^{27} 28$

Prevalence ratios (PR) for the respiratory symptoms were calculated by means of log binomial regression analyses ${ }^{29}$ to assess the association between health symptoms and outcomes of nasal lavage before and after the shift. As health symptoms were recorded only once per subject, NAL outcomes were first reduced to one value for before and after the work shift, by calculating the median value of repeated NAL measurements per subject. These median values were then dichotomised at the population median (based on the median value of each person): 1442 cells/ml, $190 \mathrm{pg} / \mathrm{ml}$ for IL8, $1.1 \mathrm{pg} / \mathrm{ml}$ for IL6, and detectable concentrations of TNF $\alpha$ and IL1 $\beta$.

\section{RESULTS}

Descriptive characteristics of the research population are listed in table 1 . Waste collectors were not sensitised to moulds as no specific IgE against mould allergens was found in waste collectors, whereas three control subjects $(27 \%)$ had increased IgE against mould allergens (all single allergen sensitisation to either Aspergillus species, Cladosporium species or Aspergillus fumigatus). Sensitisation to common allergens was found in both waste collectors and controls; IgE against grass pollen was $22 \%$ in collectors and $45 \%$ in controls, house dust mite $17 \%$ and $9 \%$, birch pollen $0 \%$ and $27 \%$, and cat dander $8 \%$ and $0 \%$. Total IgE was increased $(>100 \mathrm{kU} / \mathrm{l})$ in $25 \%$ of the collectors and $36 \%$ of the controls. Of the collectors and controls, $40 \%$ and $63 \%$ were atopic, defined as increased total IgE or specific IgE against common allergens or both.

In total 120 full shift personal exposure measurements were available for statistical analysis after excluding 11 samples due to technical measurement errors. No clear differences in exposure levels for different types of waste (organic versus non-organic or residual waste) were found. Highest dust, endotoxin, and glucan exposures $(\mathrm{p}<0.05$, table 2$)$ were found while loading waste. Estimated variance in components were 0.51 and 0.34 for dust, 1.08 and 0.22 for endotoxin, and 1.49 and 0.14 for glucan. Thus, day to day variability in exposure was large, relative to differences in exposure between people, especially for endotoxin and glucan.

A total of 268 NAL fluids was collected from waste collectors and 57 from controls. The recovery of nasal lavage fluid was the same for waste collectors and controls both before and after the work shift. Average nasal lavage fluid recoveries were $5.8 \mathrm{ml}$ (SD 1.5) and $5.8 \mathrm{ml}$ (SD 1.4) before the work shift, and $6.2 \mathrm{ml}$ (SD 1.4) and $6.0 \mathrm{ml}$ (SD 1.1) after the work shift for waste collectors and controls, respectively. Cells in NAL fluid consisted predominantly of neutrophils (mean percentage $55 \%$ for collectors and 54\% for controls) and epithelial cells (both $44 \%)$, whereas eosinophils $(0.7 \%$ and $2.1 \%)$ and mononuclear cells $(0.3 \%$ and $0.2 \%)$ were only occasionally present. Results from the regression analyses adjusted for autocorrelation are presented in figure 1. At the beginning of the week, no significant differences between waste collectors and controls in NAL inflammatory marker concentrations were found. Whereas, at the end of the week, waste collectors had higher concentrations of total cells (before shift 1.9-fold $p=0.090$; and after shift 3.3-fold $\mathrm{p}=0.002$ ), and higher concentrations of IL8 (before and after the shift 1.8 -fold; $\mathrm{p}=0.016$ ) than controls. Significant $(p<0.10)$ different effects across the week in waste collectors versus controls were. No significant differences between collectors and controls were found in concentrations of IL6, TNF $\alpha$, and ILI $\beta$. Estimated variance components between and within person were 0.89 and 1.00 for total cells, 0.53 and 0.23 for IL8, and 0.79 and 0.39 for IL6. Analyses restricted to people who had worked in their present job for more than 6 months (excluding about $21 \%$ of collectors, table 1) gave similar results. Two other possible confounding variables, smoking and age, were not associated with any of the lavage variables, and analyses adjusting for smoking and age did not significantly change the results (regression coefficients that reflect the difference between collectors and controls changed with maximal $-7 \%$ to $+14 \%$, data not shown). Atopic people had higher values for IL8 and lower number of cells, but the differences were not significant. Correction for atopy and a separate analyses for atopic and non-atopic people did not give any different results.

After/before work shift ratios, as a measure of acute effects of NAL inflammatory markers adjusted for autocorrelation are

Table 2 Exposure levels of inhalable dust, endotoxin from microbial agents, and $\beta(1 \rightarrow 3)$-glucans in domestic waste collectors

\begin{tabular}{|c|c|c|c|c|c|c|c|c|c|}
\hline & \multicolumn{3}{|c|}{ Inhalable dust $\left(\mathrm{mg} / \mathrm{m}^{3}\right)$} & \multicolumn{3}{|c|}{ Endotoxin $\left(\mathrm{EU} / \mathrm{m}^{3}\right)$} & \multicolumn{3}{|c|}{$\beta(1 \rightarrow 3)$-Glucan $\left(\mu \mathrm{g} / \mathrm{m}^{3}\right)$} \\
\hline & $\mathrm{Nd} / \mathrm{N} \pi$ & GM (GSD) & Min-Max & $\mathrm{Nd} / \mathrm{N} \pi$ & GM (GSD) & Min-Max & $\mathrm{Nd} / \mathrm{N} \pi$ & GM (GSD) & Min-Max \\
\hline Overall & $17 / 120$ & $0.58(2.6)$ & $<0.2-9.1$ & $2 / 120$ & $39.4(3.2)$ & $<4-7182$ & $20 / 118$ & $1.29(3.6)$ & $<0.26-30.8$ \\
\hline \multicolumn{10}{|l|}{ Job. task: } \\
\hline Driving & $8 / 33$ & $0.41(2.2)$ & $<0.2-2.2$ & $1 / 33$ & $25.4(2.4)$ & $<4-124$ & $6 / 32$ & $0.89(2.9)$ & $<0.26-5.9$ \\
\hline Driving or loading & $6 / 32$ & $0.52(2.7)$ & $<0.2-5.0$ & $0 / 32$ & $35.8(2.9)$ & $8-422$ & $6 / 32$ & $1.23(3.7)$ & $<0.26-24.8$ \\
\hline Loading & $3 / 54$ & $0.74(2.7)^{* *} \dagger$ & $<0.2-9.1$ & $1 / 54$ & $53.4(3.7)^{* *}$ & $<4-7182$ & $8 / 53$ & $1.62(3.9)^{*} \ddagger$ & $<0.26-30.8$ \\
\hline \multicolumn{10}{|l|}{ Waste type: } \\
\hline Organic & $13 / 44$ & $0.49(3.1)$ & $<0.2-9.1$ & $1 / 44$ & $41.4(3.5)$ & $<4-7182$ & $9 / 43$ & $1.20(4.1)$ & $<0.26-30.8$ \\
\hline Residual & $3 / 53$ & $0.59(2.3)$ & $<0.2-8.9$ & $1 / 53$ & $35.0(2.9)$ & $<4-422$ & $10 / 52$ & $1.22(3.5)$ & $<0.26-14.8$ \\
\hline Organic or residual†† & $0 / 16$ & $0.89(2.4) \S$ & $0.3-5.0$ & $0 / 16$ & $53.4(4.0)$ & $9-2279$ & $1 / 16$ & $1.89(3.1)$ & $<0.26-24.8$ \\
\hline Other & $1 / 5$ & $0.42(1.9)$ & $<0.2-0.8$ & $0 / 5$ & $23.7(2.4)$ & $8-73$ & $0 / 5$ & $1.04(2.3)$ & $0.39-2.5$ \\
\hline
\end{tabular}

${ }^{*} p<0.05 v$ driving in mixed effects analyses adjusted for auto correlation and type of collected waste; ${ }^{*} p<0.01 v$ driving in mixed effects analyses adjusted for auto correlation and type of collected waste; $t p<0.05 v$ driving or loading in mixed effects analyses adjusted for auto correlation and type of collected waste; $\ddagger \mathrm{p}<0.10 v$ driving or loading in mixed effects analyses adjusted for auto correlation and type of collected waste; $\S p<0.05 v$ organic waste in mixed effects analyses adjusted for auto correlation and job tasks; Inumber of non-dectable samples/total number of samples; ††predominantly $(13 / 16)$ collection of separated organic and residual waste at the same time. GM, geometric mean; GSD, geometric SD. 

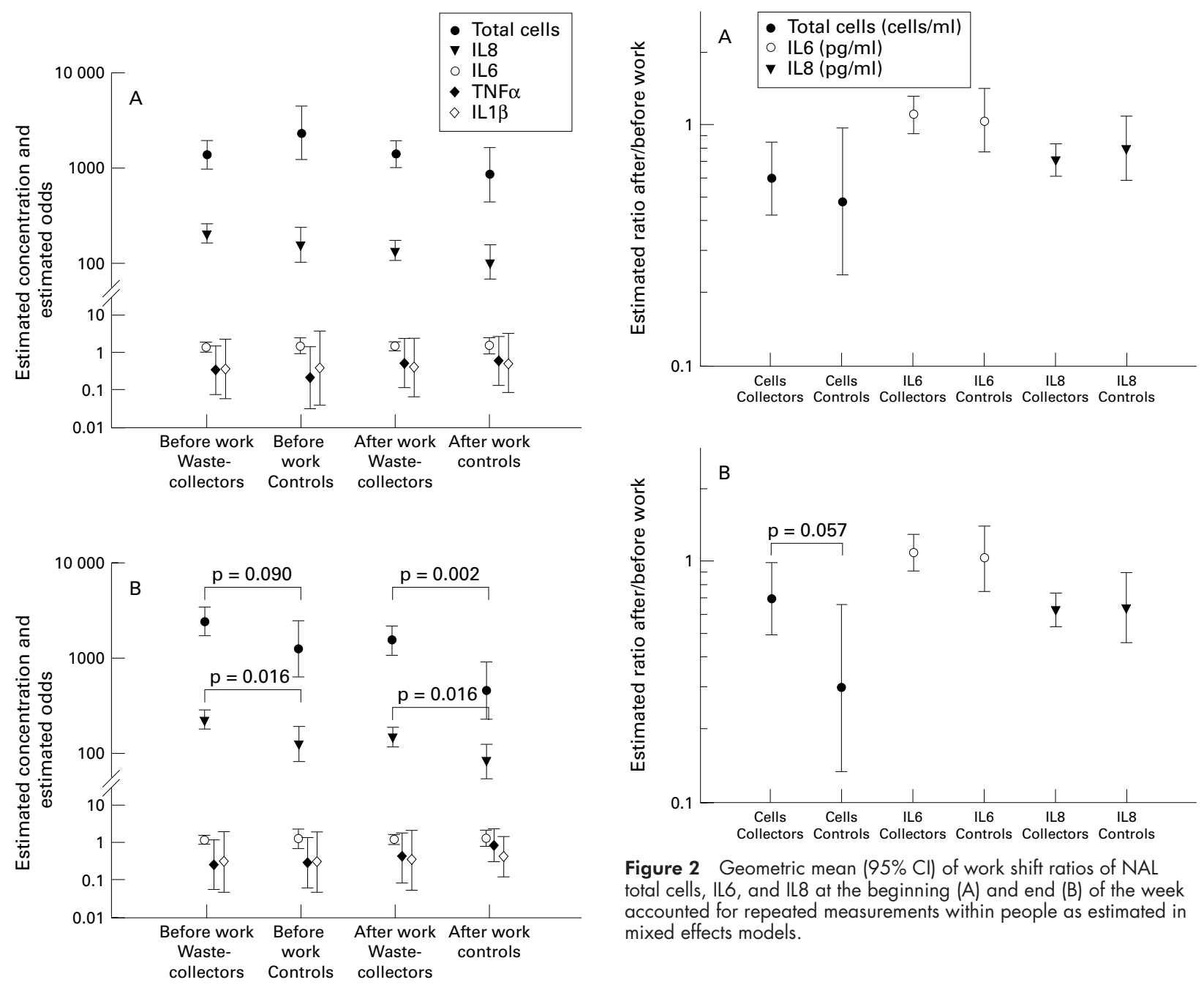

Figure 2 Geometric mean $(95 \% \mathrm{Cl})$ of work shift ratios of NAL total cells, IL6, and IL8 at the beginning (A) and end (B) of the week accounted for repeated measurements within people as estimated in mixed effects models.

Figure 1 Geometric mean $(95 \% \mathrm{Cl})$ of concentrations in NAL fluid of total cells $($ cells $/ \mathrm{ml}), \mathrm{IL} 8(\mathrm{pg} / \mathrm{ml})$, and IL6 $(\mathrm{pg} / \mathrm{ml})$, and the odds for detectable TNF $\alpha$ and ILI $\beta$, at the beginning (A) and at the end (B) of the week accounted for repeated measurements within subjects as estimated in mixed effects models.

summarised in figure 2. No differences between waste collectors and controls were found at the beginning of the week. At the end of the week the after/before ratio of total cells was increased 2.3 -fold $(\mathrm{p}=0.057)$ in waste collectors compared with controls. Adjustment for smoking and age did not significantly affect the results (data not shown). Estimates of the variance components between and within subjects were 0.14 and 1.80 for total cells, 0.07 and 0.30 for IL8, and 0.03 and 0.54 for IL6.

As across week effects were found in NAL inflammatory markers before the work shift, associations between inflammatory markers and exposure concentrations were assessed with after work shift NAL concentrations only instead of after/before work shift ratios (table 3). Generally, after shift total cell and IL8 concentrations both at the beginning and at the end of the week, were positively associated with exposure concentrations of the same day as the NAL was performed $(\mathrm{p}<0.05$ for IL8 and dust exposure). Moreover, after shift NAL concentrations at the end of the week were associated with approximates of week exposures (summed exposures of the beginning and end of the week); particularly IL8 concentrations were significantly associated with dust and endotoxin exposures $(p<0.05)$. No clear associations between concentrations of IL6 and exposures were found. After shift NAL

concentrations were not associated with job tasks or type of waste (data not shown).

Prevalence of respiratory symptoms and associations between respiratory symptoms and NAL inflammatory markers - total cells and IL8-are listed in table 4. Prevalence of health symptoms was slightly higher in waste collectors than in controls. Increased (above median) after shift IL8 concentrations were more common in subjects reporting respiratory symptoms, such as cough, cough with phlegm, wheezing, stuffy nose, and runny nose (PR range 1.6-7.7, $\mathrm{p}<0.05$ ). Respiratory symptoms were also, but only weakly, associated with increased total cell concentrations after the shift (PR range 1.5-2.3, $\mathrm{p}<0.10$ ). No associations were found between respiratory symptoms and dichotomised values of other inflammatory markers (IL6, TNF $\alpha$, and IL1 $\beta$ ). Analyses adjusting for collector/control status or current smoking and age showed similar results (data not shown). Separate analyses for collectors showed generally similar but slightly increased associations.

\section{DISCUSSION}

In this study, we showed signs of increased upper airway inflammation and respiratory symptoms in waste collectors compared with controls. The inflammation was shown at the end of the working week by higher concentrations of total cells and IL8 before and after the shift, and higher cross shift cell counts in NAL fluid. No differences between waste collectors and controls were found for IL6, TNF $\alpha$, and ILI $\beta$ in NAL fluid. The main types of cells found in the NAL fluid were neutrophils and epithelial cells, whereas eosinophils were only occasionally found, which is indicative for a non-immune 
Table 3 Relation in waste collectors between concentrations after a work shift of total cells, IL6, and IL8 in NAL fluid and personal exposure concentrations on the same day as NAL was performed (day of exposure) or a proxy for accumulated exposure for a week (sum of exposures) approximated by summing the exposures at the beginning and the end of the week

\begin{tabular}{|c|c|c|c|}
\hline Exposure to & Total cells & IL8 & IL6 \\
\hline \multicolumn{4}{|c|}{ Day of exposure at the beginning of the week: $\dagger$} \\
\hline Total dust $\left(\mathrm{mg} / \mathrm{m}^{3}\right)$ & $2.26(0.36$ to 14.02$)$ & $1.93(0.53$ to 7.03$)$ & $0.91(0.16$ to 5.12$)$ \\
\hline Endotoxin $\left(\mathrm{EU} / \mathrm{m}^{3}\right)$ & $1.17(0.25$ to 5.39$)$ & $2.34(0.84$ to 6.55$)$ & $2.13(0.51$ to 8.89$)$ \\
\hline Glucans $\left(\mu \mathrm{g} / \mathrm{m}^{3}\right)$ & $2.37(0.40$ to 14.04$)$ & $2.16(0.62$ to 7.59$)$ & $0.86(0.16$ to 4.68$)$ \\
\hline \multicolumn{4}{|c|}{ Day of exposure at the end of the week: $\dagger$} \\
\hline Total dust $\left(\mathrm{mg} / \mathrm{m}^{3}\right)$ & $1.35(0.28$ to 6.50$)$ & $2.92(1.09 \text { to } 7.84)^{*}$ & $0.55(0.09$ to 3.46$)$ \\
\hline Endotoxin $\left(\mathrm{EU} / \mathrm{m}^{3}\right)$ & 0.55 (0.13 to 2.33$)$ & $2.42(0.90$ to 6.52$)$ & $0.28(0.05$ to 1.70$)$ \\
\hline Glucans $\left(\mu \mathrm{g} / \mathrm{m}^{3}\right)$ & $0.30(0.07$ to 1.24$)$ & $1.27(0.46$ to 3.50$)$ & $0.27(0.04$ to 1.60$)$ \\
\hline \multicolumn{4}{|c|}{ Sum of exposures during the week: $\ddagger$} \\
\hline Total dust $\left(\mathrm{mg} / \mathrm{m}^{3}\right)$ & $1.88(0.27$ to 13.33$)$ & $5.31(1.26 \text { to } 22.34)^{*}$ & $2.66(0.25$ to 28.57$)$ \\
\hline Endotoxin $\left(E U / \mathrm{m}^{3}\right)$ & $1.00(0.22$ to 4.61$)$ & $3.12(1.27 \text { to } 7.71)^{*}$ & $2.28(0.32$ to 16.16$)$ \\
\hline Glucans $\left(\mu \mathrm{g} / \mathrm{m}^{3}\right)$ & $1.44(0.13$ to 16.23$)$ & 4.38 (0.72 to 26.64$)$ & $0.31(0.02$ to 4.45$)$ \\
\hline \multicolumn{4}{|c|}{$\begin{array}{l}\text { * } p<0.05 \text {; †association between concentration of marker in NAL and personal exposure measured on the } \\
\text { day of NAL; †association between concentration of marker in NAL and the sum of personal exposures } \\
\text { measured on the day of NAL at the beginning and at the end of the week. } \\
\text { Results are expressed as relative increases (ratio }(95 \% \mathrm{CI}) \text { ) in NAL concentrations after a work shift } \\
\text { associated with a difference of } 2 \mathrm{GSDs} \text { in exposure. }\end{array}$} \\
\hline
\end{tabular}

Table 4 Prevalence of respiratory symptoms and prevalence ratios (PR) of respiratory symptoms for above versus below median NAL concentrations of total cells and IL8 in waste collectors and controls

\begin{tabular}{|c|c|c|c|c|c|c|}
\hline & \multirow{2}{*}{\multicolumn{2}{|c|}{ Prevalence (\%) }} & \multicolumn{4}{|c|}{ Prevalence ratio } \\
\hline & & & \multicolumn{2}{|c|}{ Total cells } & \multicolumn{2}{|l|}{ IL8 } \\
\hline & Control & Collector & Before & After & Before & After \\
\hline \multicolumn{7}{|l|}{ Chronic symptoms: } \\
\hline Cough $>3$ months in past $2 y$ & 20.0 & 12.8 & 0.79 & 0.45 & 1.26 & 1.98 \\
\hline Cough with phlegm $>3$ months in past $2 y$ & 0.0 & 13.0 & 1.30 & 1.54 & $>1.47 \S$ & $7.71^{*}$ \\
\hline contemporaries on the flat & 0.0 & 8.5 & 0.63 & 0.53 & 1.89 & 0.53 \\
\hline Wheeze ever & 13.3 & 29.8 & 1.39 & 0.95 & 1.39 & $2.04 \dagger$ \\
\hline Wheeze $>1$ week in past $2 y$ & 6.7 & 14.9 & 0.63 & 1.58 & 1.89 & 2.64 \\
\hline Asthma attacks ever & 6.7 & 12.8 & 1.58 & 0.26 & 1.58 & 2.11 \\
\hline \multicolumn{7}{|l|}{ Symptoms at any time during the past y: $\ddagger$} \\
\hline Cough & 21.4 & 43.2 & 1.02 & $1.80 \dagger$ & 1.40 & $2.52^{* *}$ \\
\hline Cough with phlegm & 14.3 & $37.8 \dagger$ & 1.78 & $2.00 \dagger$ & $2.80 \dagger$ & $2.36^{*}$ \\
\hline Wheeze in the chest & 14.2 & 21.6 & 1.39 & 1.33 & 1.51 & $4.28^{*}$ \\
\hline Shortness of breath & 7.1 & 16.2 & 1.48 & 0.80 & 1.61 & 2.44 \\
\hline Dyspnoea & 7.1 & 10.8 & 2.37 & 3.00 & 2.58 & 2.75 \\
\hline Chest tightness & 7.1 & 13.5 & 1.19 & 2.00 & 3.23 & 1.83 \\
\hline Blocked nose & 42.9 & 62.2 & 1.13 & 1.22 & 1.43 & $1.71^{*}$ \\
\hline Runny nose & 50.0 & 56.8 & 1.25 & $1.50 \dagger$ & 1.16 & $1.59^{*}$ \\
\hline Itching nose or sneezing & 21.4 & $62.2^{* *}$ & 0.95 & 1.47 & 1.45 & 1.15 \\
\hline Throat irritation & 14.3 & 29.7 & 1.34 & $2.33 \dagger$ & 1.03 & $2.14 \dagger$ \\
\hline
\end{tabular}

inflammation mediated by neutrophils as described previously in the waste industry. ${ }^{5}$ This was furthermore supported by the observed increased levels of IL8, a strong chemoattractant of neutrophils, and by the finding that IgE sensitisation against fungi was rarely found in either waste collectors and controls. Serum IgG antibody titres against fungi and actinomycetes were the same for waste collectors and controls (data not shown), which has recently also been shown by others. ${ }^{30}$

Although exposure concentrations of organic dust in waste collectors were lower than previously described for compost workers, ${ }^{6}$ signs of inflammatory responses were still found, but were less pronounced. Significant differences between waste collectors and controls in markers of upper airway inflammation (both before and after the shift) were found, but only at the end of the week, suggesting an across week effect. Concentrations of NAL variables in controls showed a strong decline during the week, probably due to a prolonged washout effect 2-3 days after the first NAL, which has been described previously in other studies. ${ }^{6132}$ Assuming a comparable washout effect in both groups, the less pronounced decline in NAL concentrations during the week for waste collectors can only be explained by an enhanced and probably subchronic inflammatory process in the nasal mucosa of collectors. Similar across week effects were not found in our previous study in more highly exposed compost workers, ${ }^{6}$ which might have been due to the design of that particular study as controls were only measured at the beginning of the week. However, in that study signs of subchronic inflammation were shown by increased concentrations of inflammatory markers in the NAL of the most highly exposed workers compared with controls before the work shift. ${ }^{\circ}$

No differences between waste collectors and controls were found for the proinflammatory cytokines IL6, TNF $\alpha$, and ILI $\beta$ in NAL fluid. Although those cytokines are thought to play a 
crucial part in the inflammatory processes, concentrations of them in NAL fluid have been studied only rarely, showing no consistent results. ${ }^{33}{ }^{34}$ Thus the reason for the lack in response of those cytokines remains uncertain.

In the present study in waste collectors, concentrations of inflammatory markers after the shift were positively associated with exposure concentrations. So far, associations between inflammatory markers in NAL fluid and occupational exposure concentrations have hardly been reported. The exposure-response relation found was more pronounced for total dust exposure than for endotoxin or glucan exposure alone, suggesting that other currently unidentified agentsfor instance peptidoglycans - in the dust, besides endotoxin and glucan, may also play a part. ${ }^{35}$

The availability of repeated exposure and NAL measurements allowed calculation of variance components between and within subjects, where the variance between subjects reflects differences between people and the variance within subjects the day to day variation within a person. Our data showed that between and within subject variability was not the same for each NAL marker, as the total variance for IL6 and total cell concentrations was larger than for IL8 concentrations. Variability between subjects was about twice that of variability within subjects, thus showing larger differences in concentrations of NAL inflammatory markers between people than within people, which has been described previously. ${ }^{32}$ The variability of NAL inflammatory markers between and within subjects did not change after correction for being a collector or a control or time of NAL or exposure (data not shown), which has been reported previously by Hauser et al..$^{32}$ This suggests that differences between people in responses exists independently of exposure, which may be due to other undetermined factors-such as individual susceptibility - that have been described for endotoxin related airway responsiveness. ${ }^{17} 3637$

In the present study, an association between respiratory symptoms and NAL variables was shown by increased concentrations of IL8 and total cells after the shift in subjects reporting respiratory symptoms. An analysis including exposed workers only did overall yield higher risk ratios, suggesting that at least part of the association between NAL outcomes and respiratory symptoms is related to occupational exposure. To our knowledge, only one other small study in bakers has reported increased concentrations of NAL variables in the presence of nasal symptoms. ${ }^{38}$ In that study associations between symptoms and NAL were only found in bakers and not in controls.

In conclusion, waste collectors showed signs of increased upper airway inflammation and showed a slightly higher prevalence of respiratory symptoms compared with controls. Exposure to organic dust probably underlies the non-immune inflammation characterised by attraction and infiltration of neutrophils, resulting in respiratory symptoms.

\section{ACKNOWLEDGEMENTS}

We are indebted to the waste collectors and the waste collecting facilities for their participation and cooperation in the study. We also thank Isabella van Schothorst, Jack Spithoven, and Siegfried de Wind for their technical assistance in exposure measurements and laboratory analyses, and Professor B Brunekreef for reviewing the manuscript. This study was financially supported by the Ministry of Social Affairs and Employability, The Netherlands Organisation for Scientific Research (NWO), and the European Commission (BMH4-CT960105).

\section{Authors' affiliations}

I M Wouters, S K M Hilhorst, P Kleppe, G Doekes, J Douwes, C Peretz, D Heederik, Institute for Risk Assessment Sciences (IRAS), Division of Environmental and Occupational Health, Utrecht University, The Netherlands
C Peretz, Sackler School of Medicine, Institute for Environmental Research, Tel-Aviv University, Israel

\section{REFERENCES}

1 Nersting L, Malmros P, Sigsgaard T, et al. Biological health risk associated with resource recovery, sorting of recycling waste and composting. Grana 1991;30:454-7.

2 Sigsgaard T, Malmros P, Nersting L, et al. Respiratory disorders and atopy in Danish refuse workers. Am J Respir Crit Care Med 1994;149: 1407-12.

3 Zuskin E, Mustajbegovic J, Schachter EN, et al. Airway function and respiratory symptoms in sanitation workers. J Occup Environ Med 1996;38:522-7.

4 Ivens UI, Ebbehoj N, Poulsen OM, et al. Season, equipment, and job function related to gastrointestinal problems in waste collectors. Occup Environ Med 1997:54:861-7.

5 Thorn J, Beijer L, Rylander R. Airways inflammation and glucan exposure among household waste collectors. Am J Ind Med 1998;33:463-70.

6 Douwes J, Wouters I, Dubbeld H, et al. Upper airway inflammation assessed by nasal lavage in compost workers: a relation with bio-aerosol exposure. Am J Ind Med 2000;37:459-68.

7 Poulsen OM, Breum NO, Ebbehoj N, et al. Collection of domestic waste. Review of occupational health problems and their possible causes. Sci Total Environ 1995;170:1-19.

8 Nielsen EM, Breum NO, Nielsen BH, et al. Bioaerosol exposure in waste collection: a comparative study on the significance of collection equipment, type of waste and seasonal variation. Ann Occup Hyg 1997; 41:325-44

9 vanTongeren $M$, vanAmelsvoort $L$, Heederik D. Exposure to organic dusts, endotoxins, and microorganisms in the municipal waste industry. Int J Occup Environ Health 1997;3:30-6.

10 Kramer MN, Kurup VS, Fink JN. Allergic bronchopulmonary aspergillosis from a contaminated dump site. Am Rev Respir Dis 1989; 140:1086-8.

11 Allmers $\mathrm{H}$, Huber H, Baur X. Two year follow-up of a garbage collector with allergic bronchopulmonary aspergillosis (ABPA). Am J Ind Med 2000;37:438-42

12 Fogelmark B, Sjostrand $M$, Rylander R. Pulmonary inflammation induced by repeated inhalations of $\beta(1->3)$-D-glucan and endotoxin. Int J Exp Pathol 1994;75:85-90.

13 Rylander $\mathbf{R}$, Jacobs RR. Endotoxins in the environment: a criteria document. Int J Occup Environ Health 1997;3:S1-48.

14 Rylander R, Persson K, Goto H, et al. Airborne $\beta(1-3)$-glucan may be related to symptoms in sick buildings. Indoor Environ 1992;1:263-7.

15 Eduard W, Douwes J, Mehl R, et al. Short term exposure to airborne microbial agents during farm work: exposure-response relations with eye and respiratory symptoms. Occup Environ Med 2001;58:113-18.

16 Ulmer AJ. Biochemistry and cell biology of endotoxins. Int J Occup Environ Health 1997:3:S8-17.

17 Michel O. Human challenge studies with endotoxins. Int J Occup Environ Health 1997;3:S18-25.

18 Wouters,I, Douwes,J, Sigsgaard, T et al. A questionnaire to assess work related symptoms among workers handling household waste (a preliminary version was used). http://www.waste.envmed.gu.se/ quest.html 1999.

19 Biersteker K, Dijk WH, Eissens JBMF, et al. Ervaringen me geneeskundig onderzoek op CARA bii gemeentepersoneel te Rotterdam 1970-1. T Soc Geneesk 1974;52:158-62. (In Dutch, abstract in English.)

20 Hollander A, Doekes G, Heederik D. Cat and dog allergy and total lgE as risk factors of laboratory animal allergy. J Allergy Clin Immunol 1996;98:545-54.

21 Rylander R, Peterson Y, Donham KJ. Questionnaire evaluating organic dust exposure. Am J Ind Med 1990;17:121-6.

22 Doekes G, Douwes J, Wouters IM, et al. Enzyme immunoassays for total and allergen specific $\lg \mathrm{E}$ in population studies. Occup Environ Med 1996;53:63-70.

23 Kenny LC, Aitken R, Chalmers C, et al. A collaborative European study of personal inhalable aerosol sampler performance. Ann Occup Hyg 1997;41:135-53.

24 Douwes J, Versloot P, Hollander A, et al. Influence of various dust sampling and extraction methods on the measurement of airborne endotoxin. Appl Environ Microbiol 1995;61:1763-9.

25 Douwes J, Doekes G, Montijn R, et al. Measurement of $\beta(1 \rightarrow 3)$-glucans in the occupational and home environment with an inhibition enzyme immunoassay. Appl Environ Microbiol 1996;62:3176-82.

26 Helsel DR. Less than obvious: statistical treatment of data below the detection limit. Environmental Science and Technology 1990;24:1766-74.

27 Kleinbaum DG, Kupper LL, Muller KE, et al, Applied regression analysis and multivariable methods. Pacific Grove, California: Brooks/Cole, 1998:798

28 SAS Institute. SAS/STAT Software: changes and enhancements through release 6.12. Cary, NC: SAS Institute, 1997:1167.

29 Skov T, Deddens J, Petersen MR, et al. Prevalence proportion ratios: estimation and hypothesis testing. Int J Epidemiol 1998;27:91-5.

30 Bünger J, Antlauf-Lammers M, Schulz TG, et al. Health complaints and immunological markers of exposure to bioaerosols among biowaste collectors and compost workers. Occup Environ Med 2000;57:458-64. 
31 Koren HS, Hatch GE, Graham DE. Nasal lavage as tool in assessing acute inflammation in response to inhaled pollutants. Toxicology 1990;60: 15-25.

32 Hauser R, Kelsey KT, Christiani DC. Variabilty of nasal lavage polymorphonuclear leucocyte counts in unexposed subjects: its potential utility for epidemiology. Arch Environ Health 1994:49:267-72.

33 Steerenberg PA, Fischer PH, Gmelig Meyling F, et al. Nasal lavage as tool for health effect assessment of potochemical air pollution. Hum Exp Toxicol 1996;15:111-19.

34 Danuser B, Rebsamen H, Weber C, et al. Lipopolysaccharide-induced nasal cytokine response: a dose-response evaluation. Eur Arch Otorhinolaryngol 2000;257:527-32.
35 Zhiping W, Malmberg P, Larsson BM, et al. Exposure to bacteria in swine-house dust and acute inflammatory reactions in humans. Am J Respir Crit Care Med 1996;154:1261-6.

36 Michel O, Duchateau J, Sergysels R. Effect of inhaled endotoxin on bronchial reactivity in asthmatics and normal subjects. J Appl Physiol 1989:66:1059-64.

37 Kline JK, Cowden D, Hunninghake GW, et al. Variable airway responsiveness to inhaled lipopolysaccharide. Am J Respir Crit Care Med 1999; 160:297-303.

38 Brisman J, Toren $\mathrm{K}$, Lillienberg $\mathrm{L}$, et al. Nasal symptoms and indices of nasal inflammation in flour-dust-exposed bakers. Int Arch Occup Environ Health 1998;71:525-32.

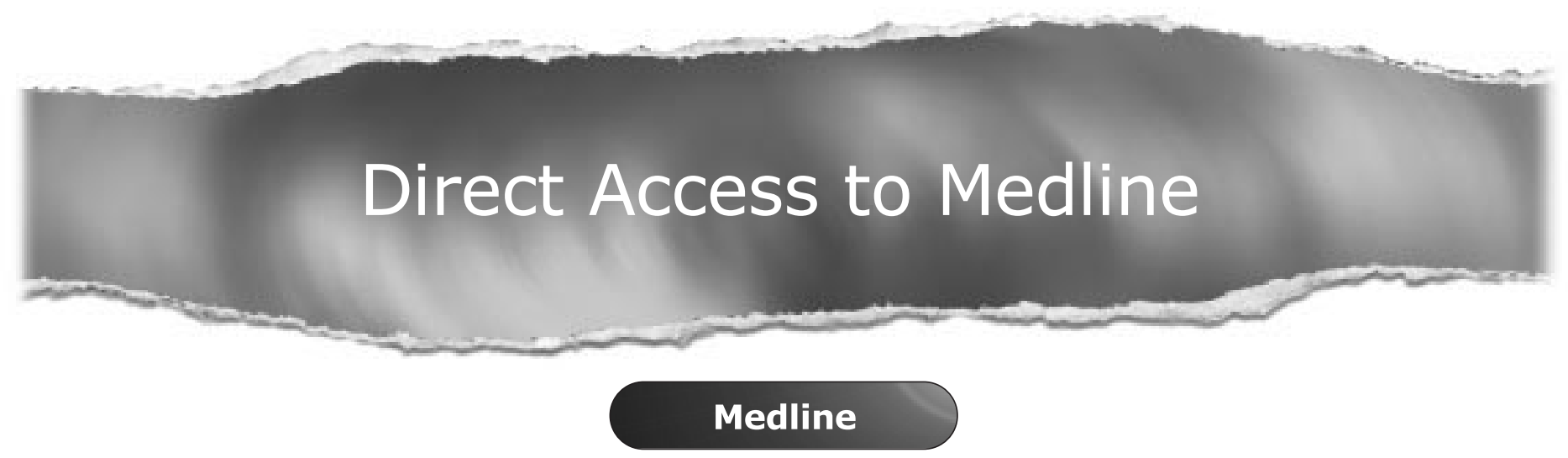

Link to Medline from the homepage and get straight into the National Library of Medicine's premier bibliographic database. Medline allows you to search across 9 million records of bibliographic citations and author abstracts from approximately 3,900 current biomedical journals.

www.occenvmed.com 


\section{LETTERS}

\section{Mortality from cardiovascular diseases and exposure to inorganic mercury}

Paolo Boffetta and his coworkers presented a comprehensive cohort study comprising 6784 male and 265 female workers from four mercury mines and mills in Spain, Slovenia, Italy, and the Ukraine. ${ }^{1}$ The expected number of deaths were derived from the national rates specific for sex, age, and calender period. Slovenia was the only country with an increased mortality of ischaemic heart disease among men (SMR $1.66,95 \%$ CI 1.35 to 2.02 ). In the Slovenian mine, dust measurements showed concentrations between 30 and 70 $\mathrm{mg} / \mathrm{m}^{3}$ with $10-35 \%$ free silica in the 1960 s, and about $40 \mathrm{mg} / \mathrm{m}^{3}$ in the 1970s. An increased mortality from pneumoconiosis was present in all countries. Mortality from ischaemic heart disease was positively correlated with duration of employment but not with cumulative exposure to mercury. Smoking habits was an unlikely confounder as mortality from diseases strongly asssociated with tobacco smoking — such as bronchitis, emphysema, and asthma-was not increased and mortality from lung cancer showed only a small increase (SMR 1.19). The purpose of this letter is to discuss further a possible relation between silica exposure and ischaemic heart disease (IHD).

A recently published study comprised 4626 industrial sand workers exposed to crystalline silica. ${ }^{2}$ The study showed a higher standardised mortality ratio regarding IHD (SMR 1.22, 95\% CI 1.09 to 1.36 ). Smoking might hypothetically be responsible for $2-4 \%$ of this increase.

A Swedish case-control study comprised 26847 men with myocardial infarctions; for each case, two controls were selected from the study base through random sampling, stratified by age, county, and socioeconomic group. The second highest risk was found among stonecutters and carvers (RR 1.9, 95\% CI 1. to 3.4). This high risk could not be explained by differences in smoking habits.

A cohort consisted of 597 miners from North Karelia in Finland employed for at least

If you have a burning desire to respond to a paper published in Occupational and Environmental Medicine, why not make use of our "rapid response" option?

Log on to our website (www.occenvmed.com), find the paper that interests you, and send your response via email by clicking on the "eletters" option in the box at the top right hand corner.

Providing it isn't libellous or obscene, it will be posted within seven days. You can retrieve it by clicking on "read eletters" on our homepage.

The editors will decide as before whether to also publish it in a future paper issue. three years in a copper mine or a zinc mine. ${ }^{4}$ The excess mortality was mainly due to IHD 44 were observed, the expected number was 22.1 based on the general male population, and the North Karelian expected number was $31.2(\mathrm{p}<0.05)$

A cohort of 3971 white South African gold miners was followed from the beginning of 1970. Most of the miners worked that year and the age of the workers was 39-54 years. The participants of the study were followed for nine years. A case-referent analysis was conducted comprising the miners who had had at least $85 \%$ of their service in gold mines. Ten years of underground mining was associated with a risk ratio of $1.5(p=0.004)$ regarding IHD after adjustment for smoking, blood pressure, and body mass index.

A large cohort comprised 68241 miners as well as pottery workers from south central China. ${ }^{6}$ The participants were employed between 1972 and 1974 and followed until 1989. There was an increased mortality due to IHD (SMR $1.25,95 \%$ CI 1.05 to 1.45 ). Smoking habit was unlikely to be responsible for this risk as the mortality from lung cancer was lower than expected (SMR 0.8, 95\% CI 0.7 to $0.9)$. There was no significant trend regarding mortality due to IHD when medium and high dust exposed workers (RR 1.16) were compared with low dust exposed workers (RR $0.65)$. Silicotics did not have an increased mortality due to IHD (RR 1.1, 95\% CI 0.7 to $1.8)$

A general hypothesis about exposure to inhaled particles and the occurrence of IHD can be expressed in the following way. Long term inhalation of particles retained in the lungs will create a low grade inflammation associated with an increase in plasma fibrinogen. The high concentration of fibrinogen will increase the likelihood for blood clotting and thereby the risk for myocardial infarction and IHD. ${ }^{78} \mathrm{~A}$ high concentration of fibrinogen in plasma is an established risk factor for IHD. An increased concentration of fibrinogen has been observed among tunnel construction workers after a workshift with a dust exposure of less than $2 \mathrm{mg} / \mathrm{m}^{3}{ }^{10}$ Thus dust exposure in general and silica exposure in particular could be interesting to discuss in relation to ischaemic heart disease in this study by Boffetta and coworkers.

B Siögren

Work Environment Toxicology, Institute of Environmental Medicine, Karolinska Institutet, SE-171 77 Stockholm, Sweden

J Holme, B Hilt

Department of Occupational Medicine, University Hospital of Trondheim, N-7006 Trondheim, Norway

\section{References}

1 Boffetta P, Sällsten G, Garcia-Gómez M, et al. Mortality from cardiovascular diseases and exposure to inorganic mercury. Occup Environ Med 2001:58:461-6.

2 Steenland K, Sanderson W. Lung cancer among industrial sand workers exposed to crystalline silica. Am J Epidemiol 2001:153:695-703.

3 Hammar N, Alfredsson L, Smedberg M, et al. Differences in the incidence of myocardial infarction among occupational groups. Scand J Work Environ Health 1992;18:178-85.

4 Ahlman K, Koskela R-S, Kuikka P, et al. Mortality among sulfide ore miners. Am J Ind Med 1991;19:603-17.
5 Wyndham $\mathrm{CH}$, Bezuidenhout BN, Greenacre M, et al. Mortality of middle aged white South African gold miners. $\mathrm{Br} J$ Ind Med 1986:43:677-84

6 Chen J, McLaughlin JK, Zhang J-Y, et al. Mortality among dust-exposed Chinese mine and pottery workers. J Occup Med 1992:34:311-16.

7 Seaton A, MacNee W, Donaldson K, et al. Particulate air pollution and acute health effects. Lancet 1995;345: 176-8.

8 Sjögren B. Occupational exposure to dust: inflammation and ischaemic heart disease. Occup Environ Med 1997;54:466-9.

9 Danesh J, Collins R, Appleby P, et al. Association of fibrinogen, C-reactive protein, albumin, or leukocyte count with coronary heart disease. JAMA 1998;279:1477-82.

10 Hilt B, Qvenild T, Holme J, et al. Increase in interleukin- 6 and fibrinogen after dust exposure in tunnel construction workers. Occup Environ Med 2002:59:9-12.

\section{Joint action of smoking and asbestos exposure on lung cancer}

This subject has long been bedevilled by unwarrantable assumption and circular argument. Why should there be only two possible hypotheses of interaction (additive and multiplicative)? Theory expects multiplicativity; epidemiology can seldom reject this hypoth esis; so theory is "accepted", and deviation from multiplicativity must be explained away. Resolution is made especially difficult because the nature of the data imposes very large error; also it has to be assumed that the exposed smoked as many cigarettes as the unexposed, and that smokers and nonsmokers were exposed equally.

Thus the "comprehensive" review by Lee was to be welcomed. However, discrepancies, particularly with another review, ${ }^{2}$ demanded discussion: this letter is the result.

From almost 40 "results" in 25 reports, Lee makes two selections to confirm the well known facts that asbestos can increase lung cancer risk in non-smokers and that the additive theory (of independent action) does not explain many of the data. Then, for 16 results, Lee calculates a statistic $V$; for an observed multiplicative interaction, $V=1$. The weighted average $V=0.90$ (95\% CI: 0.67 to 1.20) leads to Lee's conclusion. ${ }^{1}$ Repair of (acknowledged) imperfections (one misquoted result; two incorrect omissions) reduced $V$ only slightly, to 0.83 ( $95 \%$ CI: 0.63 to 1.08): for nine cohorts and nine case-referent studies, respectively, $V=0.63$ and 1.08 , a "significant" difference $(\mathrm{p}=0.049)$.

There are, however, other imperfections: two cohorts ${ }^{3}{ }^{4}$ broke the rule of independence; in another, ${ }^{5}$ asbestos had a minuscule (protective) effect on lung cancer in both nonsmokers and smokers (that is, no action, so no interaction); and in a Chinese cohort, ${ }^{6}$ risks from cigarette smoke were dramatically lower than in the West. After exclusion, the cohorts $V=0.54$ (95\% CI: $0.35-0.82)$, and the difference between types is much wider $(\mathrm{p}=0.017)$

Problems with case-referent designs are well known; here they are compounded by impure definitions of non-smokers and by retrospective assessment of exposure. It is clear from personal experience over five 
decades that, unless obtained from employers' records, job histories can be quite unreliable, even in basic facts, especially when reported by proxies. The assumption that the interactions between smoking and exposure to asbestos plus other carcinogens and between smoking and asbestos alone take the same form is untested and so indefensible. Thus, Lee's grounds for his unprecedented incorporation of the Italian study in which all concerned were exposed to PAHs, ${ }^{7}$ namely, that subjects in many studies would have been exposed to "other" carcinogens, far from justifying inclusion, provide strong additional reasons for excluding all such studies, the majority of the case-referent studies in particular. It becomes obvious that inferences from the latter cannot overthrow conclusions from the cohorts.

The potential risks from dusty coal reinforce the need to exclude the Chinese cohort. ${ }^{6}$ Undoubtedly, the North American insulation workers were not exposed only to 4-12 fibres/ml of chrysotile, ${ }^{8}$ so there is a good case for discarding this result, although it forms a cornerstone of the evidence for multiplicativity. On the other hand, the study of crocidolite miners ${ }^{9}$ might be taken into account, despite faults. ${ }^{2}$ The resultant is $V=0.47$ (95\% CI: 0.29 to 0.75 ).

Lee proceeds from $V=0.83$ (for 18 studies), noting that the significance of the difference between study types is not great, and "is removed" by an (admittedly dubious) adjustment of the lowest $V$. He "sides with other reviewers" and includes all data, concluding that "they do not clearly allow rejection of the simple multiplicative relationship".

Despite some doubt about the "best" estimate of $V$ from cohort studies, most reasonable people would accept that it is $<1$, as shown even by Lee's $V=0.63$, with $\mathrm{p}=0.018$.

Therefore, the multiplicative hypothesis is not generally satisfactory. Nor, of course, is the additive hypothesis, although it does fit some data sets very well. ${ }^{10}$

Evidently, interaction takes several forms.

\section{F D K Liddell}

Joint Departments of Epidemiology \& Biostatistics and Occupational Health, McGill University, Montreal, Canada H3A 1A2; fdkl@aol.com

\section{References}

1 Lee PN. Relation between exposure to asbestos and smoking jointly and the risk of lung cancer. Occup Environ Med 2001:58:145-53.

2 Liddell FDK. The interaction of asbestos and smoking in lung cancer. Ann Occup Hyg 2001;45:341-56.

3 Selikoff IJ, Hammond EC. Multiple risk factors in environmental cancer. In: Fraumen $\mathrm{JF} \mathrm{Jr}$, ed. Persons at high risk of cancer; an approach to cancer etiology and control. New York: Academic Press, 1975:467-83.

4 Hammond EC, Selikoff IJ, Seidman H. Asbestos exposure, cigarette smoking and death rates. Ann N Y Acad Sci 1979;330:473-90

5 Meurman LO, Pukkala E, Hakama M. Incidence of cancer among anthophyllite asbestos miners in Finland. Occup Environ Med 1994;51:421-5.

6 Zhu H, Wang Z. Study of occupational lung cancer in asbestos factories in China. Br J Ind Med 1993;50: 1039-42.

7 Pastorino U, Berrino F, Gervasio A, et al. Proportion of lung cancers due to occupational exposure. Int $J$ Cancer 1984;33:231-7.

8 Selikoff IJ, Hammond EC, Seidman H. Mortality experience of insulation workers in the United States and Canada, 1943-1976. Ann N Y Acad Sci 1979;330:91-116.

9 deKlerk NH, Musk AW, Armstrong BK, et al. Smoking, exposre to crocidolite, and the incidence of lung cancer and asbestosis. $\mathrm{Br} J$ Ind Med 1991:48:412-17.

10 Liddell FDK, Armstrong BG. The combination of effects on lung cancer of cigarette smoking and exposure in Quebec chrysotile miners and millers. Ann Occup Hyg 2002;46:5-13.

\section{Author's reply}

Having read Liddell's paper ${ }^{1}$ and the comments he expressed in his letter and at a recent meeting, it is useful to clarify where we agree and disagree. Originally I included estimates $1-16$ shown in table 1 , and estimated $V$, the ratio of the asbestos relative risk in smokers to that in non-smokers, as $0.90(95 \% \mathrm{CI}$ : 0.67 to 1.20 ). Omitting estimate 18 was an unfortunate error, and I also agree with Liddell that it is better to include estimate 17 and replace estimate 13 by estimate 19 . Accounting for this reduces $V$ to 0.83 (95\% CI: 0.63 to 1.08 ).

Liddell also suggests excluding estimates 4 , 11,12 , and 14, but for reasons I consider unconvincing. He would exclude estimate 4 as the population was exposed to PAHs. However, virtually all populations have exposure to carcinogens other than asbestos or tobacco smoke and anyway exposure to other carcinogens may simply multiply risk by about the same factor in each of the four groups being studied, little affecting the nature of the joint relation of asbestos and smoking to lung cancer. He would exclude estimate 11 because of low smoking risks, but these are typical of China $^{2}$ and do not invalidate the study. He would exclude estimate 12 as no asbestos effect was seen, but doing so based on

Table 1 Assessing the multiplicative relationship of smoking and asbestos in lung cancer risk

\begin{tabular}{|c|c|c|c|c|c|}
\hline & Estimate* & Study type & $V(95 \% \mathrm{Cl})$ & Heterogeneity $\chi^{2}$ & Degrees of freedom \\
\hline 1. & DeKlerk & $\mathrm{CC}$ & $1.25(0.19$ to 8.08$)$ & & \\
\hline 2. & Martischnig & $\mathrm{CC}$ & 2.89 (0.87 to 9.62$)$ & & \\
\hline 3. & Pastorino, no PAH & $\mathrm{CC}$ & $0.64(0.10$ to 4.06$)$ & & \\
\hline 4. & Pastorino, PAH & $\mathrm{CC}$ & 1.01 (0.13 to 7.94$)$ & & \\
\hline 5. & Bovenzi & $\mathrm{CC}$ & $0.86(0.31$ to 2.39$)$ & & \\
\hline 6. & Kjuus & $\mathrm{CC}$ & 1.52 (0.39 to 5.93 ) & & \\
\hline 7. & Blot, Georgia & $\mathrm{CC}$ & 1.26 (0.54 to 2.93$)$ & & \\
\hline 8. & Blot, Virginia & $\mathrm{CC}$ & 0.84 (0.39 to 1.81$)$ & & \\
\hline 9. & Blot, Florida & $\mathrm{CC}$ & $0.72(0.22$ to 2.36$)$ & & \\
\hline 10. & McDonald & $\mathrm{P}$ & $0.61(0.25$ to 1.49$)$ & & \\
\hline 11. & Zhu & $\mathrm{P}$ & $1.60(0.43$ to 5.90$)$ & & \\
\hline 12. & Meurman & $P$ & 1.19 (0.07 to 20.4$)$ & & \\
\hline 13. & Berry, 1960-70 M+F & $\mathrm{P}$ & $0.61(0.10$ to 25.7$)$ & & \\
\hline 14. & Selikoff and Hammond & $P$ & $1.22(0.32$ to 10.4$)$ & & \\
\hline 15. & Selikoff & $\mathrm{p}$ & $0.19(0.07$ to 0.61$)$ & & \\
\hline 16. & Hammond & $P$ & 0.95 (0.47 to 2.21$)$ & & \\
\hline 17. & Berry, 1971-80 M+F & $P$ & $0.33(0.13$ to 1.25$)$ & & \\
\hline 18. & Liddell $^{3}$ & $\mathrm{P}$ & 0.56 (0.20 to 1.56$)$ & & \\
\hline 19. & Berry, 1960-70 F & $P$ & $1.47(0.22$ to 50.0$)$ & & \\
\hline \multicolumn{6}{|c|}{ Original analysis } \\
\hline \multicolumn{2}{|c|}{ Estimates $1-16$} & All & 0.90 (0.67 to 1.20$)$ & 14.88 & 15 \\
\hline \multicolumn{6}{|c|}{ Revised analysis } \\
\hline \multicolumn{2}{|c|}{ Estimates $1-12,14-19$} & All & 0.83 (0.63 to 1.08 ) & 18.39 & 17 \\
\hline \multirow{2}{*}{\multicolumn{2}{|c|}{$\begin{array}{l}\text { Estimates } 1-9 \\
\text { Estimates } 10-12,14-19\end{array}$}} & $\mathrm{CC}$ & 1.08 (0.74 to 1.59$)$ & 4.33 & 8 \\
\hline & & $P$ & 0.63 (0.43 to 0.92$)$ & 10.17 & 8 \\
\hline \multicolumn{6}{|c|}{ Revised analysis with exclusions } \\
\hline \multicolumn{2}{|c|}{ Estimates $1-3,5-10,15-19$} & All & 0.79 (0.59 to 1.05$)$ & 17.00 & 13 \\
\hline \multicolumn{2}{|c|}{ Estimates $1-3,5-9$} & $\mathrm{CC}$ & 1.09 (0.74 to 1.60$)$ & 4.33 & 7 \\
\hline \multicolumn{2}{|c|}{ Estimates $10,15-19$} & $P$ & $0.54(0.35$ to 0.82$)$ & 6.95 & 5 \\
\hline
\end{tabular}

* References and fuller details given elsewhere ${ }^{4}$ except where stated.

$C$, case-control; $P$, prospective.

$V$ is the ratio of the asbestos relative risk in smokers to that in non-smokers. 
observed results can cause bias. He would exclude estimate 14 as the study population is a subset of that for estimate 15 . However, the follow up period was much longer for estimate 14 (1943-74) than for estimate 15 (1967-76), so omitting it would have lost data. Anyway, omitting estimates 4, 11, 12, and 14 only has a minor effect, $V$ reducing to 0.79 (95\% CI: 0.59 to 1.05 ) (table 1).

At face value, the combined data appear reasonably homogeneous and compatible with the multiplicative model. However, as Liddell notes, estimates for prospective and case-control studies differ. Using my revised analysis, prospective studies give $V=0.63$ (95\% CI: 0.43 to 0.92 ) and case-control stud ies $V=1.08$ (95\% CI: 0.74 to 1.59 ), a statistically significant difference $(\mathrm{p}=0.049)$. With Liddell's four suggested exclusions, $V=0.54$ (95\% CI: 0.35 to 0.82 ) for prospective studies and $V=1.09$ (95\% CI: 0.74 to 1.60 ) for casecontrol studies, with $\mathrm{p}=0.017$

He stresses this significant difference, rejects the case-control data due to data unreliability, use of proxies, and inclusion of ex or light smokers in the reference group and argues that inferences should be drawn only from the prospective studies. I regard these arguments as dubious. The significance of the difference is not great and is removed $(\mathrm{p}=0.089$ for the revised data) if the estimate of $V$ for the one study (estimate 15 showing a very low value is revised based on "best available evidence" rather than on death certificate diagnosis (though this revision is itself questionable). Prospective studies may be limited by failure to record changes in smoking status after follow up starts. The Quebec prospective study ${ }^{3}$ obtained data from proxies; many case-control studies did not. While data on accuracy of exposure is no doubt better in prospective studies, I side with other reviewers in considering the whole data.

The asbestos relative risk may be somewhat lower in smokers than non-smokers, but the available data do not clearly reject the simple multiplicative relation. More complex models of joint action might indeed fit the data better but in view of the general problems with the data, it seems doubtful whether more detailed statistical analysis would shed any greater insight.

$P$ Lee

P N Lee Statistics \& Computing Lto Hamilton House, 17 Cedar Road, Sutton, Surrey SM2 5DA, UK

\section{References}

1 Liddell FDK. The interaction of asbestos and smoking in lung cancer. Ann Occup Hyg 2001:45:341-56.

2 Liu Z. Smoking and lung cancer in China: combined analysis of eight case-control studies. Int J Epidemiol 1992:21:197-201.

3 Liddell FDK, Thomas DC, Gibbs JW, et al. Fibre exposure and mortality from pneumoconiosis, respiratory and abdomina malignancies in chrysotile production in Quebec, 1926-75. Singapore Ann Acad Med 1984:13(suppl 2):340-4.

4 Lee PN. Relation between exposure to asbestos and smoking jointly and the risk of lung cancer. Occup Environ Med 2001;58:145-53.

\section{Occupational exposure to magnetic fields}

While Savitz's point of view expressed in the editorial $^{1}$ that epidemiological methodology faces its limits when the risk is small exposure assessment is poor, and biological insight is lacking, must be reinforced, it is not so clear whether or not this view is applicable to the field of exposure to extremely low frequency electromagnetic fields (ELF EMF). Unfortunately some of the studies that could contribute to an evaluation of the relation between ELF EMF exposure and cancer have serious deficits. This is apparently also the case for the paper by Sorahan and colleagues. ${ }^{2}$ First it has to be stressed that there is no such diagnostic entity as "brain tumour". Brain tumours comprise a heterogeneous group of both malign and benign neoplasms generating from different tissues, with different growth rates and other essentially different features (for an overview see Black ${ }^{3}$. The authors do not even mention the number of cases of different tumour types, let alone discuss why they feel that all these completely different entities could be affected by a single cause.

Another crucial point is latency. The only essential criterion of causation in the assessment of epidemiological evidence is "temporal relation". It is crucial that provisions are made to allow for biologically reasonable latencies. Instead the authors report on estimates based on the most recent (!) five years of exposure, thus choosing an exposure metric that has nothing to do with the vast majority of brain tumours that have latencies of at least five (but many 20 or more) years (for example, Strojan $e t a l^{4}$ ). Most of the brain tumours will have been already initiated before the point in time the exposure was accumulated to give the indicator the authors have chosen. At least the last 10 years prior to diagnosis of the tumour have to be truncated in computation of the exposure metric and all cases occurring earlier than 10 years after onset of exposure have to be omitted.

To choose Tesla-years as the exposure variable is also questionable because we do not know whether or not risk is cumulative. A more sophisticated exploitation of information on exposure could be expected from the authors. For example, time spent under peak exposures (e.g. exceeding $10 \%$ of the exposure limit) would be a meaningful surrogate. Tesla-years introduces an equivalence that has never shown to be meaningful: that exposure duration and intensity are commutative (that is, 10 years exposure to $1 \mu \mathrm{T}$ is equivalent to one year exposure to $10 \mu \mathrm{T}$ )

Overall the study in its presented form cannot be considered to contribute to the assessment of a relation between ELF EMF exposure and brain tumours.

M Kundi

Institute of Environmental Health, Department for Occupational and Social Hygiene, Kinderspitalgasse 15, A-1095 Vienna, Austria

\section{References}

Savitz DA. Occupational exposure to magnetic fields and brain cancer. Occup Environ Med 2001·58:617-18.

2 Sorahan T, Nichols L, van Tongeren M, et al. Occupational exposure to magnetic fields relative to mortality from brain tumours: updated and revised findings from a study of United Kingdom electricity generation and transmission workers, 1973-97. Occup Environ Med 2001;58:626-30

3 Black PM. Brain tumors. N Engl J Med 1991;324:1471-6.

4 Strojan P, Popovic M, Jereb B. Secondary intracranial meningiomas after high-dose cranial irradiation: report of five cases and review of the literature. Int J Radiat Oncol Biol Phys 2000;48:65-73.

\section{Authors' reply}

Professor Kundi implies that, in our analyses of brain tumour risks and magnetic field exposure, we only considered exposures occurring in the most recent five years. We did not. Analyses of total cumulative exposures to magnetic fields in relation to mortality risks from primary brain tumours were reported in table 3, and analyses of the potential role of recent exposures were reported in table $4 .{ }^{1}$ Confirmation of diagnosis had also been sought from cancer registration particulars. These analyses were planned in advance as tests of the main hypotheses of interest. These hypotheses had been derived from a review of the current literature, and for neither analysis was there any suggestion of magnetic field exposure being implicated in mortality risks for brain tumours. The ICD codes we used to define the health outcome and the use of micro-Tesla years as the unit of magnetic field exposure enabled our study findings to be compared to other reports. Their use appears, at least to us, to be eminently sensible. We remain open to the possibility that other exposure metrics may come to be appreciated as more biologically relevant but we doubt whether the proposal of Prof. Kundi (time spent exceeding an arbitrary percentage of a contemporaneous exposure limit) will gain favour.

We hope our study makes a useful contribution to the practice of occupational health and that employees in the UK electricity supply and transmission industry treat the findings as good news.

T Sorahan J $M$ Harrington

Institute of Occupational Health, University of Birmingham, Edgbaston, Birmingham B15 2TT, UK

\section{Reference}

1 Sorahan T, Nichols L, van Tongeren M, Harrington JM. Occupational exposure to magnetic fields relative to mortality from brain tumours: updated and revised findings from a study of United Kingdom electricity generation and transmission workers, 1973-97. Occup Environ Med 2001;58:626-30.

\section{BOOK REVIEW}

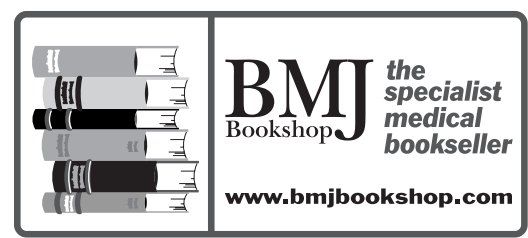

\section{Innovation in Chinese Medicine}

Elisabeth Hsu (pp 426; £55) 2001. Cambridge: Cambridge University Press. ISBN 0 521800684

With increasing popularity of Chinese medicine in the West, there has been an increasing number of books published in this field. Some of them have dealt with the philosophical aspect of Chinese medicine, and others concentrated on the diagnosis and treatments. All of them referred to ancient texts such as the Yellow Emperor's Inner Cannon and used terminology from them. The uses of 
these ancient concepts and terminology have led many to consider Chinese medicine as primitive, ritualistic, and unchanging. Such negative connotations have deterred many from studying Chinese medicine. Even if they did they felt they had to forego its theories and use the Western scientific paradigm to explain their treatment.

Elisabeth Hsu and the other authors in this book aimed to challenge this stereotype of Chinese medicine. They did so using selected examples to explain how evolution occurred in different aspects of Chinese medicine over time and the factors which motivated these changes. They showed that such changes could be brought about by the prevailing cosmological theories at the time, such as the incorporation of the system of five circulatory phases and six seasonal influences around the tenth century. Some changes were brought about by the political ideology at the time, such as the development of the new acumoxa theory in early communist China. But many are down to individuals' intuition, such as the new system of cataloguing natural pharmaceuticals by Li Shizhen in Bencao gangmu compiled in the sixteenth century. Many of the examples were chosen because they had far reaching consequences but some, notably one that was brought about for the sake of political correctness, did not have any sustainable influence.
The style of writing used in this book is one of its strengths. The reference text from which main arguments were based is cited both in Chinese and in English to avoid quoting out of context. Detailed footnote and extensive cross referencing underpin and expand the author's line of argument. Readers with scientific and medical background will appreciate such "evidence based" approach.

Its method of translation deserves to be noted separately. Chinese medicine terms have been notoriously difficult to have a standard translation, partly because they represent abstract concepts and their meaning can be different, depending on the context. Hsu used the official transcription system pinyin and Chinese characters alongside the English translation. These minimise confusion and allow readers to cross reference these terms with texts from other sources.

As well as achieving the author's objective, this book shows that Chinese medicine is not illusive and does not defy investigation. The author has shown how this could be done and her approach is different and innovative. The logical arguments in this book will appeal to professionals within the scientific community and can be a useful way to evaluate Chinese medicine.

Gilbert Shia

\section{CORRECTIONS}

We apologise for the following errors. In the paper "Low level cadmium exposure and kidney damage-the OSCAR study" (Järup et al) published in 2000 (Occup Environ Med 2000;57:668-72) the following errors were made:

(1) In the second paragraph, page 670 , and at the fourth row, page 671 , the text reads " 1.6 $\mathrm{nmol} / \mathrm{mmol}$ creatinine". It should read " 1.0 nmol/mmol creatinine" at both places.

(2) In Table 1 , " $n$ " for age for the women should be 542 and not 544 .

In the paper "Upper airway inflammation and respiratory symptoms in domestic waste collectors" (Wouters et al) published in February 2002 (Occup Environ Med 2002;59:106-12), the following errors were made:

(1) On page 108, right hand column, lines 5-7, part of the sentence was omitted. it should have read: "Estimated within and between subjects variance components of exposure concentrations were 0.51 and 0.34 for dust, 1.08 and 0.22 for endotoxin, and 1.49 and 0.14 for glucan."

(2) Table 2 heading: "from microbial agents" should have been omitted. 